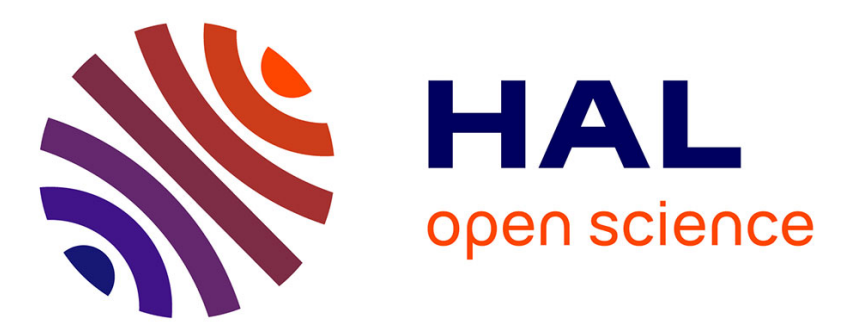

\title{
Usage of Finance Information Systems in Developing Countries: Identifying Factors During Implementation that Impact Use
}

David Kiwana, Björn Johansson, Sven Carlsson

\section{- To cite this version:}

David Kiwana, Björn Johansson, Sven Carlsson. Usage of Finance Information Systems in Developing Countries: Identifying Factors During Implementation that Impact Use. 3rd International Conference on Information and Communication Technology-EurAsia (ICT-EURASIA) and 9th International Conference on Research and Practical Issues of Enterprise Information Systems (CONFENIS), Oct 2015, Daejon, South Korea. pp.333-342, 10.1007/978-3-319-24315-3_34 . hal-01466234

\author{
HAL Id: hal-01466234 \\ https://hal.inria.fr/hal-01466234
}

Submitted on 13 Feb 2017

HAL is a multi-disciplinary open access archive for the deposit and dissemination of scientific research documents, whether they are published or not. The documents may come from teaching and research institutions in France or abroad, or from public or private research centers.
L'archive ouverte pluridisciplinaire HAL, est destinée au dépôt et à la diffusion de documents scientifiques de niveau recherche, publiés ou non, émanant des établissements d'enseignement et de recherche français ou étrangers, des laboratoires publics ou privés. 


\title{
Usage of Finance Information Systems in Developing Countries: Identifying Factors during Implementation that Impact Use
}

\author{
David Kiwana, Björn Johansson, Sven Carlsson \\ Department of Informatics, School of Economics and Management, Lund University, \\ Ole Römers väg 6, SE-223 63 Lund, Sweden \\ \{david.kiwana; bjorn.johansson; sven.carlsson\}@ics.lu.se
}

\begin{abstract}
An explorative study of factors affecting implementation and use of finance information systems (FISs) in developing countries is presented. The result is based on a field study investigating implementation of a finance information system at Makerere University, Uganda. Current literature suggests that how to implement information Systems (ISs) successfully is challenging, especially in developing countries. The research question addressed is: What factors during implementation impact use of FISs in developing countries? Empirical data was gathered through face-to-face interviews with involved stakeholders in the implementation project. Analysis was done as a within-case analysis and supports the findings of nine factors that are of specific importance in developing countries. The findings can help decision-makers in guiding implementation processes of large enterprise systems especially in the accounting and finance management disciplines in developing countries.
\end{abstract}

Keywords: ERP, Financial Information Systems, Implementation, Use, Success and Failure Factors, Developing Countries.

\section{Introduction}

Finance information systems (FISs) take financial data and process it into specialized financial reports, saving time and effort in dealing with business accounting [1], it also provide decision-makers with information to perform managerial functions [2].

While FISs have many benefits, it should be noted that putting them in place can be costly and in most cases requires a lot of training and commitment by people involved [1]. As a result many organizations find difficulties to attain the desired success during their implementations, and many critical success factors for IS implementation have been suggested, however actual evidence to devise solutions for failed projects has not been clearly established [3].

In this paper we present research that was conducted to explore factors that shape implementation and later on use of FISs in the context of developing countries. According to Mulira [3] emerging public organizational networks in developing countries work with unpredictable environments and resource scarcity that have led to higher failure rates of Information Systems (IS) implementation projects. This 
research builds on a retrospective field study describing implementation of a FIS at Makerere University (Mak) in Uganda. The FIS whose implementation was studied is a component of an integrated enterprise system called Integrated Tertiary Software (ITS), a South African software product that was installed at the University to manage finances/accounting, students' records and human resource functions.

Before proceeding to the sections that follow, it is important to clarify that finance information systems (FISs) many times are implemented as part of ERPs ([4]; [5]). This means that implementation issues that are pertinent to ERPs are largely pertinent also to implementation of FSIs. This research therefore is premised on the ideology that what is said about ERPs in terms of implementation is largely applicable to FSIs implementations as well.

The next two sections present problematic issues in IS implementation and what is known about ERP/FIS implementation. Section 4 presents the research method. This is followed by a presentation of research findings. Section 6 presents and discusses the nine factors that emerged during the analysis.

\section{Problematic Issues in IS implementation}

Research findings have reported that failure of large information systems implementations like ERPs are not caused by the software itself, but rather by a high degree of complexity from the massive changes that the systems cause in the organisations ([6]; [7]; [8]). According to Helo, et al. [7], the major problems of ERP implementations are not technologically related issues such as technological complexity, compatibility, standardisation etc., but mostly about organisational and human related issues like resistance to change, organisational culture, incompatible business processes, project mismanagement and lack of top management commitment. Furthermore, Huang and Palvia [9] has identified other issues like inadequate IT infrastructure, government policies, lack of IT/ERP experience and low IT maturity to seriously affect the adoption decision of ERPs in developing countries. What is not clear therefore is whether all such factors are exhaustively known and if so, how they (the factors) impact on eventual use of the systems considering the fact that the failure rate is still high. The failure rate of major information systems appears to be around $70 \%[5,10]$. Chakraborty and Sharma [11] state that $90 \%$ of all initiated ERP projects can be considered failures in terms of project management. Ptak and Schragenheim [12] claim that the failure rates of ERP implementations are in the range of $60-90 \%$. Helo, et al. [13] make the statement that in the worst scenarios, many companies have been reported to have abandoned ERP implementations. From this discussion it can be said that in FIS implementation, as a case of ERP implementation, the issues of concern are either technologically related or contextually related. Technologically related issues are not reported as problematic since they are probably more or less the same in different contexts. This means that the contextually related issues may be more problematic and interesting to address. Contextual factors have mainly been researched in developed country contexts, the challenge is researching these issues in a developing country context. This supports 
the need for studying: What factors during implementation impact use of FISs in developing countries?

\section{What is known about ERP/FIS Implementation?}

FISs implementation is an emblematic of complex project that constantly evolves and as it is the case with design and implementation of any complex system the aspects of leadership, collaboration and innovation are of importance in the implementation process [14]. A successful completion of a FIS implementation depends on external factors as well and the adverse effects of country-specific political economy issues and political environment [14].

Pollock and Cornford [15] argue that the need for implementation of FISs in high education sectors is a response to both internal and external factors requiring more efficient management processes due to increasing growth of the numbers of students, changes in the nature of academic work, increasing competition between institutions, increasing government pressure to improve operational efficiency, and growing diversity of expectations amongst all stakeholders [16].

\subsection{Causes of failure of ERP/FISs Implementation}

Senn and Gibson [17] point to user resistance as symptomatic of system failure as users may aggressively attack the system, rendering it unusable or ineffective, or simply avoid using it. Ginzberg [18] found that possible causes of implementation failure being user dissatisfaction with scope, user dissatisfaction with system goals, and user dissatisfaction with the general approach to the problem that the system is meant to address. In other words, system implementations are more likely to fail when they are introduced with unrealistic expectations.

As presented by Calogero [19], excessive focus on technologies rather than business user needs is one of the determinations of ERP implementations failures. Projects initiated due to technology are more likely to be unsuccessful than the business-initiated projects due to the fact that technology-initiated projects are most frequently driven by such goals as replacement of an old system with a new one which is a complicated task [20].

Lack of proper user education and practical training is another cause of a failure of IS implementation projects. According to Nicolaou [20] conducting user training upfront could cause unsuccessful ERP implementation due to limited scope of training possibilities before implementation. Kronbichler, et al. [21] say that unclear concept of nature and use of an ERP system from the users' perspective due to poor quality of training and insufficient education delivered by top management and project team also leads to failure. In developing countries where there are more challenges due to unstable infrastructure, funding and unstable social/economic organizational environment the quality of training becomes even poorer which leads to more failures of ERP implementations compared to developing countries [3]. 


\subsection{Specific issues for ERP/FIS Implementation in developing countries}

Heidenhof and Kianpour [22] claim that many African countries struggle with public financial management reforms whereby institutions, systems, and processes that deal with various aspects of public finance are weak, non-transparent, and often incapable of developing adequate budgets and providing reliable data for economic modeling.

IS implementation failures keep developing countries on the wrong side of the digital divide, turning ICTs into a technology of global inequality. IS implementation failures are therefore practical problems for developing countries that need to be addressed [23]. The information, technology, processes, objectives and values, staffing and skills, management systems (ITPOSMO) checklist adapted from Malling [23] shows that the technological infrastructure is more limited in developing countries; the work processes are more contingent in developing countries because of the more politicized and inconstant environment; developing countries have a more limited local base in the range of skills like systems analysis and design, implementation of IS initiatives, planning, and operation-related skills including computer literacy and familiarity. When it comes to management and structures organizations in developing country are more hierarchical and more centralized, and in addition the cost of ICTs is higher than in developed countries whereas the cost of labor is lower [24]. This supports that an explorative study of: What factors during implementation impact use of FISs in developing countries, are of interest.

\section{Research Method}

This research was carried out at Makerere University (Mak) through a retrospective field study, investigating aspects of implementation of the ITS (Integrated Tertiary Software) finance subsystem. Empirical data was collected by face-to-face interviews guided by semi-structured questions. Mak was selected because it has an enrolment of about 40,000 students and therefore has a potential to provide a good ground for a wide range of issues pertinent to the study.

A total of ten people were interviewed and these included the head of the finance department, the head of the IT unit, the person who was responsible for the user team, the coordinator of NORAD (Norwegian Funding Agency) in the University's Planning Unit who funded the implementation costs and six accountants from the Finance Department. The respondents were chosen based on their relevance to the research question and closeness to the subject matter rather than their representativeness. The interviewer (one of the researchers) has a position at Mak and was to some extent involved in the implementation process of the system. The interviewer's position at Mak at that time was in the IT unit of Mak as Systems Manager with the role of assisting various units in the university in acquisition and implementation of central software resources.

Questions asked during interviews were mainly in four areas: general information about the organisation and the system, information on how the implementation was done, and information on how the system was being run and used. Analysis of the data was done using within-case analysis whereby the general patterns and themes 
were identified. The analysis aimed at identification of factors that were presented as influential in the implementation process by the respondents. The next section presents briefly the case and then the identified factors are presented and discussed.

\section{Presentation of Research Findings.}

Makerere University is a public university in Uganda with an enrolment of approximately 40,000 students and 5,000 staff members. The university procured an integrated enterprise system called Integrated Tertiary Software (ITS) to be used in finance management, students' administration and human resource management. In this study we focussed on the finance subsystem. Next we present why the FIS was bought and why; how and when was the time for the implementation decided; how was the actual implementation done.

\subsection{What was the origin of the idea to buy the FIS and why?}

In regard to issues for why the system was implemented, one thing that was mentioned by almost all interviewees was a problem of lack of efficiency in managing fees payments of students due to very large numbers of students. The Head of the Finance Department said: "the problem was the number of students and the most risky area was revenue. As a finance manager that was my main focus. The rest we could afford to handle manually. For example, with the expenditure the vouchers are with you, but with revenue you would not know who has paid and from what faculty". The Senior Assistant Bursar and the person who headed the implementation team said: "The privatisation scheme that was introduced in the nineties brought an increase in student population. Mak could no longer accurately tell how much money was being received and reports could no longer be given in a timely manner". The Head of the IT unit said: "The main motivating factor for the implementation was the big number of students and lack of efficiency that subsequently followed".

In addition donor influence and best practice also played big roles in influencing the decision to procure the system. The Head of the IT unit said: "Donors were looking at institutions within the country to create efficiencies, and automation was being seen as the best practice that was being proposed elsewhere. Mak had started looking ahead towards automation but already there was a move by development partners requiring public institutions to improve performance. So Mak's big numbers coincided with the push by the development partners to automate systems and being the highest institution of learning in the country, Mak was a prime choice for donors to fund". The Head of the IT unit continued to say that automation was not decided by the players like the head of the finance and head of academic records. "What they presented was just increasing challenges to support top management in their bid to solicit funding from the donors for the automation." In other words, according to the Head of the IT unit, the push for implementation was a top-down approach motivated by a position that institutions in developing countries needed to comply with donor requirements. The Head of IT summarised by saying that "things actually happened 
in parallel. Donors came in to look for efficiency and they found Mak already grappling around to see how to solve the problems of inefficiency".

Another influencing factor had to do with best practice. The Head of Finance said: "When I joined the university everything was manual and the thinking at the time was how to make Mak ICT enabled. That urged us to look into that area and we wanted to catch up with other universities so we said that we would look for funders because government wouldn't". The Head of the IT unit head also said "the adoption of systems in many institutions of higher learning, and automation of functions whether administrative or academic is not a reinventing the wheel, most institutions follow best practice. What is important is that you have a champion to introduce the automation; you need to have the funding and the team players. Then at the end you need to have a change management team that can influence and affect the changes. So it is essentially adopting best practice and that is what Mak did."

\subsection{When and how was the time to start the implementation decided?}

According to Tusubira [25] it was during a conference for all heads of departments that was organised by the Vice Chancellor in 2000 to discuss a question of ICT development in the university. A resolution was made to develop an ICT policy and master plan that was aimed at defining a strategy that the university would take in its bid to develop the use of ICT in its management systems. The master plan comprised of all the planned ICT activities for the university for a period of five years (2001 to 2004) and the implementation mandate was given to DICTS. Among the activities was the implementation of the university information systems that included the finance system.

In summary the factors found motivating the implementation were:

- The need by the university top management to give development partners satisfaction that Mak had the necessary capacity to manage finance information efficiently.

- A need from the finance department to find a way of managing increasing student fees records in time as a result of increasing student numbers following issuance of a policy by Mak to start admitting privately sponsored students in the 1990's.

- Influence from best practice that pointed to automation of systems as a must way to go during that time as seen by top management and DICTS.

- Need by Mak under the stewardship of the Directorate for ICT Support to execute the activity of implementing information systems that included the FIS as had been prescribed in the University ICT master plan for 2001-2004.

- Funds provided by a developing partner, NORAD under stewardship of the Mak Planning Unit, which had to be utilised within a specific period, 2001-2004, being available.

\subsection{How the actual implementation was done}

After the system was procured, several activities related to the actual implementation took place. These are shortly described below in chronical order: 1) installation and 
customising the system, 2) formation of the implementation teams, 3) training, about 30 people were trained over a period of about two months, and 4) user acceptance and commissioning: by the end of 2006 all the modules were found to be functional although only three were being used at that time (i.e., student debtors, cash book and electronic banking) and the system was commissioned in February 2007.

\section{Identified implementation factors impacting FIS use}

A large part of the interviewees (more than 60\%) said that the system and especially the interface for capturing data was not easy to use and this seemed to have discouraged many people from using the system. One accountant specifically said: "the system is not user friendly, for example, for a transaction to be completed you have to go through several steps, and in case you forgot a step you have to repeat". We label this as a: Factor of System Usability.

There were too many bank accounts as each unit in the university had its own bank accounts and supervision of staff was not adequate. It was therefore very hard to have all the cashbooks across the university up-to-date to enable a complete set of reports to be generated in a timely manner. The head of implementation said "the cash books were too many as a result of the big number of bank accounts which were almost over 200. The people working on them and who were scattered in many different units could not all update them in a timely manner to have any meaningful reports generated in a timely manner". We suggest categorising this as a Factor Evaluation of Staff Performance.

The study showed that there was a lack of a clear plan for how persons should stop using the older systems. When one accountant was asked why the modules to do with the expenditure failed to be operationalized whereas the revenue module for student debtors was a great success he said "the form of record keeping at that time was in decentralized manner, so supervising people was not easy and secondly the people were allowed to continue with the older systems. Student debtors succeeded only because there was no alternative". Talking about the same, the Head of the Finance department said: "In the beginning the problem was the number of students, and the most risky area was revenue. So there was much focus on revenue. The rest you could afford to handle manually. For example, with the expenditure the vouchers are with you, but with revenue you do not know who has paid and from what faculty" We suggest categorising this as a Factor of Change Management Program.

It was found that a lot more was acquired in terms of modules than required to solve the actual problem that was prevailing. This was found to be due to the fact that the push to implement was from the top to the bottom because the funds (which were being provided by development partners) were readily available.

When the Head of the IT unit was asked whether the story would have been different if Mak was to finance the project from its own internal budget instead of donor funds she said: "If there were budget constraints whereby Mak would have to look for donors then Mak would think a lot more about how that money would be spent, and if Mak was using their own money they would have asked the finance department from inception more, because they would have said that we do not have 
money tell us only those critical modules that have to be funded within a constrained budget". The Head of the IT unit added: "but we have a top down approach supported by challenges from below that already has funding coming from some source aside so we do not have to involve them too much because they have already given us their challenges to support our case and we got the money. And once we put up a bid and the best system came up it was adopted in its entirety". In conclusion the Head of the IT unit said: "budgeting constraints would have forced a more concise scheme and more involvement of the user department. But this was not the case. They were there to support the cause by only challenges as the money had been got from somewhere else". We suggest categorising this as a Factor of Project Management.

According to the Head of the IT unit, the human resource structure had not been fully designed to be compliant with the new automation aspect. She said "The human resource had been used to using a manual system and now they had to take on a new system, and with too many modules, and the structural adjustments started being done after the system was installed". She added: "It was much later after evaluating the system when a decision was made to strike off some particular modules. If this had been done at the beginning, the people would have easily mastered the system and the university would have saved money." We suggest categorising this as a Factor of Change Management Program.

It was found that support was always never timely causing frustrations to many people. One accountant commented: "Support was always not timely and this rendered people to fall back to their original work practices in order to meet targets. We suggest to categories this as Factor of Technical support and Effective IT unit Another accountant said: "Nobody took initiative to operationalise the entire system". We suggest categorising this as Factor of Top Management Support.

It was observed that some people did not know and did not believe that adequate searching for a suitable system was done before the system was procured. One accountant commented that "the university should have taken time to do more research and come up with a system that would perform better. ITS was only at Mak with no any comparisons within Uganda". It was discovered the belief of the accountant was not correct because it was established from other sources that before the decision to procure was made Mak sent a team of people in a foreign university where a similar system was being used to find more about it. This means that there was lack of information with some people and we therefore suggest categorising this as a factor of Effective Communication.

It was found that all the trainees (about 30) were pulled together in one big group and it turned out to be very difficult for each individual to get direct contact with the trainers. Secondly after training the trainers immediately went back to South Africa (where they had come from) keeping very far away from users who were just maturing. The head of the user team said: "the whole department was trained together as one group for two months, but in addition the trainers should have also done individualised training, and they should have remained in close proximity".

And when asked to comment on the fact that during training people were taken through the entire system but that the situation on ground did not reflect that, the Head of the Finance department said that that was the case because they were doing an implementation of this kind for the first time. He added that "People went for training only once, so after time they forgot and the problem was that there was a 
lack of people to guide Mak. The consulting firm reached a point when they would want to charge whenever they would be called and so financial implications came in. They could help on the system but they could not help on the functionalities." We suggest categorising this as a factor of Education and Training.

It was found that due to some omissions or/and deficiencies that existed in the Requirements Specifications Document, some functionalities could not adequately run. For example, when an accountant was asked whether the organisation took time to review all the relevant organisation policies to ensure that they were all adequately accommodated in the automated environment, he said: "Some were done like the registration of students but at a later time. Some were not done, for instance, the system could not handle multicurrency features for fees". In some instances the consultants would accept to quickly do the necessary rectifications and in some instances they would not, which would cause problems. We suggest categorising this as a factor of Flexible Consultants.

\section{Conclusions and future research}

The aim of this study was to answer the research question: What factors during implementation impact use of FISs in developing countries? Previous studies on FIS implementation show that the design and implementation of FIS solutions is challenging and requires development of country specific solutions to meet the associated functional and technical requirements. Previous studies also show that as a result of increased challenges in developing countries due to unstable infrastructure and unstable social economic organisational environment, the quality of training gets poorer which leads to increased implementation failures compared to the situation in developed countries. The starting point for identification of factors was system usability. From that we identify nine factors that shaped the implementation and use of the FISs. These are: Project management, evaluation of staff performance, effective communication, instituting of change management programs, provision of technical support by consultants, effective IT unit, providing education and training, top management support, and flexible consultants. These factors are related to different activities in the implementation and they all influence the results of the implementation expressed as systems usability in positive or negative directions. Future research will focus on to what extent the different factors influences use of implemented systems in developing countries.

\section{References}

[1] R. Morgan, "What are the benefits of financial information systems," http://www.ehow.com/info 7893940 benefits-financial-information-systems.html, 2014.

[2] C. J. Hendriks, "Integrated Financial Management Information Systems: guidelines for effective implementation by the public sector of South Africa: original research," South African Journal of Information Management, vol. 15, pp. 1-9, 2013.

[3] N. K. Mulira, Implementing inter-organisational service systems: An approach for emerging networks in volatile contexts: TU Delft, Delft University of Technology, 2007. 
[4] H. Bancroft, H. Seip, and A. Sprengel, Implementing SAP R/3: How to introduce a large system into a large organization, 1997.

[5] T. H. Davenport, "Putting the enterprise into the enterprise system," Harvard business review, pp. 121-31, 1998.

[6] J. E. Scott and I. Vessey, "Implementing Enterprise Resource Planning Systems: The Role of Learning from Failure," Information Systems Frontiers, vol. 2, pp. 213-232, 2000.

[7] P. Helo, P. Anussornnitisarn, and K. Phusavat, "Expectation and reality in ERP implementation: consultant and solution provider perspective," Industrial Management and Data Systems, vol. 108, pp. 1045-1059, 2008.

[8] D. Maditinos, D. Chatzoudes, and C. Tsairidis, "Factors affecting ERP system implementation effectiveness," Journal of Enterprise Information Management, vol. 25, pp. 60-78, 2011.

[9] Z. Huang and P. Palvia, "ERP implementation issues in advanced and developing countries," Business Process Management Journal, vol. 7, pp. 276-284, 2001.

[10] H. Drummond, "What we never have, we never miss? Decision error and the risks of premature termination," Journal of Information Technology, vol. 20, pp. 170-176, 2005.

[11] S. Chakraborty and S. K. Sharma, "Enterprise resource planning: an integrated strategic framework," International Journal of Management and Enterprise Development, vol. 4, pp. 533-551, 2007.

[12] C. A. Ptak and E. Schragenheim, ERP: tools, techniques, and applications for integrating the supply chain: CRC Press, 2003.

[13] P. Helo, P. Anussornnitisarn, and K. Phusavat, "Expectation and reality in ERP implementation: consultant and solution provider perspective," Industrial Management \& Data Systems, vol. 108, pp. 1045-1059, 2008.

[14] C. Dener, J. Watkins, and W. L. Dorotinsky, Financial Management Information Systems: 25 Years of World Bank Experience on What Works and What Doesn't: World Bank Publications, 2011.

[15] N. Pollock and J. Cornford, "ERP systems and the university as a "unique” organisation," Information Technology \& People, vol. 17, pp. 31-52, 2004.

[16] D. Allen and T. Kern, "Enterprise resource planning implementation: Stories of power, politics, and resistance," in Realigning Research and Practice in Information Systems Development, ed: Springer, 2001, pp. 149-162.

[17] J. A. Senn and V. R. Gibson, "Risks of investment in microcomputers for small business management," Journal of Small Business Management, vol. 19, pp. 24-32, 1981.

[18] M. J. Ginzberg, "Early diagnosis of MIS implementation failure: promising results and unanswered questions," Management Science, vol. 27, pp. 459-478, 1981.

[19] B. Calogero, "Who is to blame for ERP failure?," Sun Server Magazine, 2000.

[20] A. I. Nicolaou, "ERP systems implementation: drivers of post-implementation success," in Decision Support in an Uncertain and Complex World: The IFIP TC8/WG8. 3 International Conference, 2004, pp. 589-597.

[21] S. A. Kronbichler, H. Ostermann, and R. Staudinger, "A comparison of erp-success measurement approaches," JISTEM-Journal of Information Systems and Technology Management, vol. 7, pp. 281-310, 2010.

[22] G. Heidenhof and P. Kianpour, "Design and Implementation of Finaricial Management Systers: An African FPerspective," 2002.

[23] P. Malling, "Information systems and human activity in Nepal," Information Technology in Context: Implementing in the Developing World, Ashgate Publishing, Aldershot, 2000.

[24] R. Heeks, "Information systems and developing countries: Failure, success, and local improvisations," The information society,, vol. 18, pp. 101-112, 2002.

[25] F. F. Tusubira, "Supporting University ICT (Information and Communication Technology) Developments: The Makerere University Experience," Africa Development, vol. 30, pp. 86-97, 2005. 